\title{
As redes cognitivas na ciência da informação brasileira: um estudo nos artigos científicos publicados nos periódicos da área
}

\author{
Liliane Vieira Pinheiro \\ Mestre em ciência da informação pela Universidade Federal de Santa \\ Catarina e Bibliotecária da Universidade Regional de Blumenau \\ E-mail: lilianepinheiro@yahoo.com.br
}

Edna Lúcia da Silva

Doutora em ciência da informação pela Universidade Federal do Rio de Janeiro - CNPq/IBICT.

E-mail:edna@cin.ufsc.br

\section{Resumo}

Pesquisa que mapeou as redes cognitivas na área de ciência da informação no Brasil, a partir da análise de citações dos artigos publicados nos principais periódicos desta área, no período de 2001 a 2005. É uma pesquisa quali-quantitativa, exploratória-descritiva e documental, que tem como corpus de análise os artigos científicos publicados nas principais revistas brasileiras da área, utilizando técnicas bibliométricas, para a análise dos dados. Constata que as redes cognitivas mais significativas na ciência da informação, no Brasil, podem ser mapeadas pelas comunidades estabelecidas pelas citações. Estas comunidades são formadas devido às afinidades temáticas, o que denota uma proximidade paradigmática, e pela proximidade institucional. Conclui que, no Brasil, a ciência da informação é conduzida por um grupo de pesquisadores que interfere nas relações estabelecidas para o embasamento do desenvolvimento de estudos e pesquisas e, assim, determina o envolvimento disciplinar e interdisciplinar da área no país.

\section{Palavras-chave}

Ciência da informação. Redes cognitivas. Conhecimento científico.

The cognitive networks in information science in Brazil: a study in scientific articles published in journals of this area

\begin{abstract}
This research has mapped the cognitive networks in the area of Information Science in Brazil, based on an analysis of the citations of articles published in the main journals of this area from 2001 to 2005. It is a qualitative-quantitative, exploratory-descriptive and documental research. The corpus of analysis is the scientific articles published in the main Brazilian journals of this area. Bibliometric techniques were used for data analysis. The most important cognitive nets in Information Science in Brazil can be mapped by the communities established by the citations. These communities are established by thematic affinity, what shows a paradigmatic closeness, and by institutional relationship. The conclusion is that in Brazil Information Science is schemed by a group of researchers who handle the relations established for building up the development of studies and research and establish the disciplinary and interdisciplinary involvement of this area in Brazil.
\end{abstract}

Keywords

Information Science. Cognitive networks. Scientific knowledge.

\author{
INTRODUÇÃO
}

A ciência da informação, no decorrer de sua trajetória como área de conhecimento, é considerada uma ciência interdisciplinar em razão das relações estabelecidas com outros campos científicos (SARACEVIC, 1996). A interdisciplinaridade nessa área é vista a partir das disciplinas que a compõem e das contribuições dos outros campos do conhecimento, com seus conceitos, princípios, técnicas, métodos e teorias, e vice-versa: da ciência da informação para os demais campos do conhecimento (PINHEIRO, 1999).

Dentre os diferentes acontecimentos que permeiam as origens da ciência da informação, pode-se destacar:

- a publicação da obra Tratado de Documentação por Paul Otlet, em 1934 (SILVA; RIBEIRO, 2002);

- a publicação do artigo As we may think por Vanevar Bush, em 1945 (BARRETO, 2002; SANTOS, 2002; SARACEVIC, 1996);

- a explosão informacional que ocorre após a Segunda Guerra Mundial e a criação da American Society for Information Science, em 1960 (PINHEIRO; LOUREIRO, 1995);

- a reunião do Geórgia Institute of Technology, em 1962 (BRAGA, 1995; PINHEIRO; LOUREIRO, 1995);

- as ações do belga Paul Otlet, considerado o pioneiro da ciência, pois o seu entendimento de que o objetivo da documentação era processar informação contribuiu para as origens e evolução dessa ciência (SILVA; RIBEIRO, 2002);

- a transformação, em 1960, do American Documentation Institute em American Society for Information Science e, conseqüentemente, a transformação do periódico American Documentation em Journal of the American Society for Information Science (BRAGA, 1995; LE COADIC, 2004). 
González de Gómez (2000) sugere que a ciência da informação surgiu a partir de transformações das sociedades contemporâneas, visto que tais sociedades começam a considerar o conhecimento, a comunicação, os sistemas de significação e uso da linguagem como objetos de pesquisa científica e domínios de intervenção tecnológica. Assim, é possível vinculá-la à sociedade da informação, pois nesta nova era a informação flui em velocidades e quantidades inimagináveis, torna-se valorizada social e economicamente (TAKAHASHI, 2000).

A cientificidade desse campo pode ser vista a partir da existência de programas de pós-graduação e de veículos de comunicação e disseminação da informação e conhecimento produzido, como destacam Oliveira, Mota e Urbizagastegui Alvarado (2004). No Brasil, então já se pode afirmar que a ciência da informação é um campo de conhecimento consolidado, pois está representado por 11 programas de pós-graduação (Pontifícia Universidade Católica de Campinas, Universidade Federal da Bahia, Universidade Federal de Minas Gerais, Universidade Federal Fluminense, Universidade Federal do Rio de Janeiro, mediante convênio com Instituto Brasileiro de Informação em Ciência e Tecnologia (Ibict), Universidade de Brasília, Universidade do Estado de São Paulo/Marília, Universidade de São Paulo, Universidade Federal de Santa Catarina, Universidade Federal da Paraíba e Universidade Federal de Pernambuco) e uma linha de pesquisa em outro programa, no caso da Universidade Federal do Rio Grande do Sul. E também está representada por veículos de comunicação e disseminação, tais como Ciência da Informação, Perspectivas em Ciência da Informação, Informação e Sociedade, DataGramazero, Transinformação, Encontros Bibli, Revista Digital de Biblioteconomia e Ciência da Informação e Informação e Informação.

A ciência da informação, na perspectiva abordada neste artigo, será entendida a partir do paradigma da complexidade, o que implica o reconhecimento, como adverte Capra (2000), de que as concepções e teorias científicas são limitadas e aproximativas, de modo que a verdade científica é sempre incompleta e transitória.

Deleuze e Guattari (1995) abordam a complexidade a partir do rizoma, entendendo a realidade a partir do uno e do múltiplo, como em um processo em transformação, e com inúmeras dimensões que vão além da divergência entre sujeito e objeto. $\mathrm{O}$ rizoma, utilizado como metáfora para as redes, constitui-se de nós interligados, que conectam qualquer ponto independentemente da sua natureza; não é feito de unidades, e sim de dimensões; não tem começo nem fim, mas possui um meio pelo qual cresce e se estende (DELEUZE; GUATTARI, 1995). Os nós conectados não necessitam ser homogêneos, desde que compartilhem interesses comuns ou possuam alguma característica convergente. "Na rede, a complexidade não é um obstáculo ao conhecimento, ou, pior, um juízo descritivo, é o melhor dos adjuvantes do saber" (SERRES, 1967, p. 15). A rede, nessa visão, comporta uma pluralidade de subtotalidades.

A ciência, nesta pesquisa, foi entendida como uma rede cognitiva, na qual os cientistas e seus produtos são os nós e as citações indicam as relações entre eles. Os documentos científicos, com seu sistema de remissões a outros documentos, constituem uma rede do conhecimento científico. Na literatura, as relações entre os pesquisadores são observadas a partir de quem cita quem. As citações podem ser consideradas os elos de uma rede, na qual os pesquisadores são os nós. Os "cientistas constroem seu trabalho a partir de obras anteriores e mostram isso, mencionando-as em seus textos, em uma lista de referências" (VANZ; CAREGNATO, 2003, p. 248). Seus trabalhos, por sua vez, serão citados em trabalhos posteriores.

Dessa forma, as redes de citação podem ser denominadas redes cognitivas, pois são nós e relações que possibilitam representar o conhecimento, e se reportam à teoria da autopoiese, utilizada por Maturana e Varela (1995) e Maturana (2001), para explicar a cognição. A teoria da autopoiese tem como idéia básica que os seres vivos produzem-se continuamente a si mesmos e que seus componentes estão dinamicamente relacionados em uma rede contínua de interações (MATURANA; VARELA, 1995). Em outras palavras, é uma rede que continuamente cria a si mesma (CAPRA, 2000), remete a um sistema organizado auto-suficiente, no qual os componentes são conectados e mutuamente interdependentes. A autopoiese "é um padrão de rede no qual a função de cada componente consiste em participar da produção ou da transformação dos outros componentes da rede." É o que ocorre nas redes de citações, que relacionam os documentos, e, conseqüentemente, as idéias dos autores e o conhecimento retratado nesses documentos, de forma que tais idéias e conhecimentos influenciam a construção de novos conhecimentos, que são explicitados nos documentos científicos. As citações tecem uma rede de conversações; a ciência, segundo Maturana (2001), é um domínio cognitivo, uma rede de conversações que 
envolve afirmações e explicações de outros autores e trabalhos anteriores, que servem como instrumento de validação científica.

Nesse sentido, as citações podem ser comparadas à unidade autopoiética, utilizada por Maturana e Varela (1995) para descrever processos cognitivos. As citações compõem o texto científico, tecendo uma rede em que os elementos - as citações - são produzidos a partir de outros documentos produzidos anteriormente. E, por sua vez, sendo citado, o mesmo texto estará na origem de outros documentos. É o que Maturana e Varela (1995) denominam circularidade cognitiva, pois os pesquisadores constroem o conhecimento dentro das organizações que dão sentido ao seu trabalho, o que resulta em publicações que alimentam o fazer científico.

Para Solla Price (1965) e Foucault (1995), a ocorrência de relações entre diversos autores e trabalhos formaria uma rede tecida por possíveis relações interdiscursivas, em um dado recorte de conhecimento. Foucault (1995, p. 26) ressalta a importância dos relacionamentos de um trabalho com outros. Para esse autor, uma publicação "vai além do título, das primeiras linhas e do ponto final, além de sua configuração interna e da forma que lhe dá autonomia, está presa em um sistema de remissões a outros livros, outros textos, outras frases", que representam nós em uma rede e um feixe de relações cognitivas.

O ponto de partida, nesta pesquisa, para se tecerem as redes cognitivas será a produtividade científica dos autores. Vale lembrar que os modos de se estudar a produtividade dos autores foram estabelecidos inicialmente por Dresden (1922) e Lotka (1926). A Lei de Lotka ou Lei do Quadrado Inverso postula que alguns pesquisadores, em uma determinada área do conhecimento, produzem muito e muitos pesquisadores produzem pouco. A lei aponta para a medição da produtividade dos autores, mediante um modelo de distribuição tamanho-freqüência de autores em um conjunto de documentos e para sua aplicação requer um corpus de aplicação com longo período de abrangência, para que haja possibilidade de a produtividade dos autores aproximar-se da distribuição de freqüência prevista na lei. Essa lei tem sido testada, contestada e aperfeiçoada através dos tempos em diversos estudos nacionais e estrangeiros. No Brasil, Urbizagástegui Alvarado (2002) levantou, até o ano de 2000, mais de 200 estudos que tinham sido desenvolvidos como tentativas de replicação, critica, e/ou reformulação da Lei de Lotka.
Cabe ressaltar que a medida da produtividade científica, realizada nesta pesquisa, funcionará somente como input para possibilitar o mapeamento das redes de citações. Portanto, a aplicação e/ou testagem da aderência dos resultados desta pesquisa à Lei de Lotka não fazem parte dos objetivos da mesma, embora se reconheça a importância dos estudos que seguiram esse direcionamento.

Considerando que a ciência da informação tem a possibilidade de estudar a si mesma, esta pesquisa objetivou mapear as redes cognitivas no campo da ciência da informação no Brasil, buscando responder a seguinte questão de pesquisa: Quais são as redes cognitivas mais significativas na construção do conhecimento científico da ciência da informação, no Brasil? Na busca de respostas para esta questão, o estudo foi desenvolvido analisando as redes de autores e citações nos artigos dos periódicos científicos consolidados da área de ciência da informação, pois se acredita que tais redes retratem as relações estabelecidas entre os pesquisadores na produção do conhecimento, o que nesta pesquisa denominou-se redes cognitivas.

Para contemplar o mapeamento das redes cognitivas, foram traçados alguns objetivos complementares para serem atingidos, como identificar as comunidades que se formam, a partir das relações estabelecidas pelas citações, e detectar os autores mais influentes na construção do conhecimento da área de ciência da informação, no Brasil.

\section{PROCEDIMENTOS METODOLÓGICOS}

Para o mapeamento das redes cognitivas de pesquisadores, a partir das citações realizadas nos artigos científicos publicados nos periódicos da área de ciência da informação, no Brasil foi desenvolvida uma pesquisa documental, que teve como corpus de análise os artigos científicos nas publicações dos periódicos científicos da área de ciência da informação, no Brasil, no período de 2001 a 2005.

No Brasil, a área de ciência da informação estava representada no momento de realização da pesquisa por 10 periódicos científicos. Para fins desta pesquisa, foram selecionados os periódicos que estão mais consolidados, publicados regularmente e mais bem posicionados na classificação do Qualis na Coordenação de Aperfeiçoamento de Pessoal de Ensino Superior (Capes). O Qualis é uma classificação dos veículos de divulgação usados pelos professores e alunos dos programas de pósgraduação - principais engajados na produção do 
conhecimento científico - enquadrando os veículos em categorias indicativas de qualidade - A (alta), B (média), ou C (baixa) - e de circulação - local, nacional ou internacional (COORDENAÇÃO DE APERFEIÇOAMENTO DE PESSOAL DE ENSINO SUPERIOR, 2006). Dessa forma, foram utilizados os fascículos dos periódicos usados como veículo de disseminação das informações na área de ciência da informação, no período entre 2001 e 2005, que estavam classificados no Qualis como A Nacional. Trata-se dos fascículos publicados dos seguintes periódicos: Ciência da Informação, Transinformação, Informação e Sociedade: Estudos, Perspectivas em Ciência da Informação, Encontros Bibli: Revista Eletrônica de Biblioteconomia e Ciência da Informação e DataGramaZero: Revista de Ciência da Informação.

Como material de análise, foram utilizados os artigos científicos publicados nos periódicos mencionados, no período de 2001 a 2005. Os artigos científicos foram definidos como artigos assinados e resultantes de atividades de pesquisa e foram identificados pelas divisões internas, denominadas metodologia, resultados, conclusões (BRAGA; OBERHOFER,1982; MEADOWS, 1999; MALTRÁS BARBA, 2003).

A escolha de artigos ocorreu em razão das suas funções para a ciência e por constituírem a representação do conhecimento científico, na medida em que esse conhecimento só é válido quando publicado em periódicos científicos. A partir do exposto, foram selecionados somente os artigos que divulgavam os resultados de pesquisas científicas e que, ao longo do seu conteúdo, explicitavam os objetivos da pesquisa, o método empregado, os resultados (parciais ou completos) e as conclusões.

A coleta de dados compreendeu a captura dos dados dos artigos levantados e sua posterior inserção em um formulário eletrônico. Para tal, foram coletados os dados dos periódicos, os dados dos artigos citantes e as referências.

$\mathrm{Na}$ análise dos dados, foram usadas técnicas bibliométricas, especificamente a análise de citação e de co-citação. A análise de citação foi realizada como técnica bibliométrica capaz de mapear as relações entre os documentos citantes e os documentos citados, no todo ou em parte (BRAGA, 1972). Nesta pesquisa, a análise de citação foi utilizada mais especificamente para identificar os autores citados e as relações tecidas com os autores dos artigos citantes, o que permitiu explicitar as redes tecidas no ato de citar.
Ainda, visando à identificação das comunidades invisíveis que se formam a partir das relações estabelecidas pelas citações, foi realizada uma análise de co-citação de autores, buscando verificar quais autores que citaram os mesmos autores, formando uma comunidade em torno desses. Para operacionalizar essa análise, foram elaboradas as matrizes de citação.

Como a pesquisa visava ao mapeamento das redes mais significativas na área e a amplitude da rede obtida dificultaria a interpretação das relações encontradas, decidiu-se tecer as redes a partir dos autores mais produtivos, usando-se o conceito de redes egocêntricas. Hanneman (2001) explica que, no estudo das redes egocêntricas, são eleitos alguns nós focais e a rede é tecida a partir das relações por eles estabelecidas. Assim, ao estudar as redes, é possível investigar somente uma parte delas, pois os dados das redes completas são muito onerosos e difíceis de obter e analisar. Esse enfoque também possibilita verificar as situações individuais (HANNEMAN, 2001). A partir do exposto, optou-se por trabalhar com as redes egocêntricas com conexões com outros, neste tipo de análise faz-se uma seleção dos nós que serão o foco da investigação e verifica-se com quais outros nós eles estão ligados. Nesta pesquisa, a planilha inicial foi refinada para obter-se uma matriz com os nós que seriam investigados - os autores mais produtivos - e os autores por eles citados, aqueles com os quais os autores estão ligados.

A densidade da produção científica, nesta pesquisa, foi estabelecida por meio da contagem de freqüência das citações e co-citações de autores nos artigos. A densidade, propriedade básica da rede, é calculada a partir da razão entre as conexões presentes e o número de conexões possíveis na rede. A densidade de cada autor foi medida a partir da razão entre as conexões de cada autor (citações recebidas pelo autor) e o número total de conexões na rede (total de citações). Os autores mais incidentes nas citações representaram os nós focais e a partir deles foram tecidas as redes. Para o mapeamento dessas redes cognitivas, optou-se pela utilização dos softwares Microsoft Office Excel e Ucinet, especificamente o Netdraw (BORGATTI; EVERETT; FREEMAN, 2002), freqüentemente utilizado na análise de redes sociais. Tais softwares permitiram contabilizar os nós, construir matrizes e visualizar as conexões das redes. $\mathrm{O}$ uso do Ucinet foi útil à medida que possibilitou a representação gráfica das relações estabelecidas a partir de um foco determinado, no caso os autores mais produtivos, para representar graficamente as redes egocêntricas. 


\section{RESULTADOS: ANÁLISE E DISCUSSÃO}

Considerando-se que as redes de produção do conhecimento articulam elementos heterogêneos como saberes e coisas, inteligências e interesses (LATOUR, 1994), deve-se ressaltar que o mapeamento realizado das redes cognitivas de pesquisadores representa uma fotografia tirada em um dado momento dessa rede. E assim mostra a situação daquele momento, na verdade apenas um recorte da rede total, visto que o corpus foi limitado aos artigos científicos da área e o foco da abordagem foi proporcionado pela análise de citações no próprio corpus e contexto em que a pesquisa foi desenvolvida.

A presente pesquisa não visou mapear a estrutura da rede de co-citação, mas mapear as relações mais eminentes estabelecidas, entendidas como as redes cognitivas de pesquisadores, que foram visualizadas a partir das citações feitas nos artigos científicos publicados na área de ciência da informação, no Brasil.

\section{As redes cognitivas de pesquisadores da área de ciência} da informação, no Brasil

As citações feitas nos artigos científicos da área de ciência da informação foram utilizadas para identificar as relações tecidas entre os autores na produção do conhecimento científico dessa área, no Brasil, ou seja, as redes cognitivas. A rede é composta de nós e relações, e, quando essas relações são estabelecidas para a produção do conhecimento, as redes podem ser denominadas redes cognitivas. Na rede analisada, os nós são compostos pelos trabalhos citantes e citados, pelos autores dos artigos citantes e pelos autores dos trabalhos citados. Assim, estudar a rede cognitiva da área implica considerar não somente cada pesquisador ou o conjunto deles, mas também as relações que se estabelecem, diretamente pela colaboração e co-autoria em trabalhos, ou indiretamente por meio das citações que fazem aos mesmos documentos e autores.

Para identificar as redes mais significativas na área, optouse por trabalhar com as redes egocêntricas. As redes são mapeadas a partir de nós focais, aqui definidos como os autores mais produtivos da área, no Brasil, e suas conexões com outros.

Em uma primeira análise, a partir dos autores mais produtivos versus os autores por eles mais citados (que receberam acima de quatro citações), é possível visualizar algumas nuances da rede tecida na produção do conhecimento em ciência da informação, no Brasil.
A partir do mapa (figura 1) verificam-se as interações entre os pesquisadores, visto que estes, ao citarem os mesmos autores, compartilham as suas idéias e estabelecem uma relação indireta, cujo nó intermediário é o autor citado. É necessário destacar que parte das interações ou das citações feitas a um mesmo autor identificadas na presente pesquisa não indica o compartilhamento de suas idéias em diferentes artigos, mas é reflexo da co-autoria nos artigos utilizados na pesquisa.

Os autores citados estão representados no mapa pelo ícone quadrado, e os autores citantes, pelo círculo. A sobreposição dos ícones representa que o autor citado também é um autor citante. Isso indica que os pesquisadores que produzem o conhecimento são também autores citados, como ocorre no processo recursivo, característica da autopoiese, em que os produtos e os efeitos são simultaneamente causas e produtores daquilo que os produziu (MATURANA; VARELA, 1995). González de Gómez (2002), quando compara as redes ao modelo de inteligência distribuída, afirma que cada um e todos são tanto produtores quanto consumidores de conhecimento.

A distribuição dos trabalhos de acordo com o grau de conformidade com as normas acadêmicas corresponde com a distribuição dos autores de acordo com sua posição de poder especificamente acadêmico. Não são os posicionamentos políticos que determinam os posicionamentos das pessoas acerca das questões acadêmicas, são suas posições no campo acadêmico que animam os posicionamentos que eles adotam acerca dos temas políticos em geral, assim como acerca dos problemas acadêmicas (BOURDIEU, 1984).

$\mathrm{Na}$ rede cognitiva, os autores se relacionam ao redor dos autores citados, o que lembra uma tapeçaria, onde os fios ou os laços não estão dispostos ao acaso, mas estão arranjados em função do tecido, de forma que cada parte converge para o todo (MORIN, 1991). Assim, a tapeçaria não pode ser explicada por uma lei simples (MORIN, 1991), pois cada relação estabelecida entre os autores tem fatores intervenientes distintos.

Lembrando que a densidade é calculada a partir da razão entre as conexões presentes e o número de conexões possíveis na rede e que este parâmetro serviu de base para analisar os dados da pesquisa. Nesta pesquisa, assim, a densidade foi medida a partir da razão entre as conexões de cada autor (citações recebidas pelo autor) e o número total de conexões na rede (total de citações), constatando- 
se que, dentre os autores com maior densidade, destacamse Suzana Pinheiro Machado Mueller, Lea Velho, Ikujiro Nonaka, Maria das Graças Targino, Lena Vânia Ribeiro e Jayme Teixeira Filho.

Os autores mais densos são os mais relacionados. Entretanto, a densidade obtida nesta pesquisa não é necessariamente conseqüência da citação em vários trabalhos, ou dos autores que possuem mais capital simbólico. A densidade pode ser reflexo das relações estabelecidas com os diversos nós da rede em razão da citação que esses autores receberam em trabalhos publicados por muitos autores, multiplicando a quantidade de relações estabelecidas. Assim, o autor citado estabelece uma relação com cada autor do artigo, implicando aumento da sua densidade na rede e distorção no dimensionamento da mesma.

Alguns dos autores mais densos, como Léa Velho e Suzana Pinheiro Machado Mueller, estão também entre os autores mais citados. Nesses casos a densidade está relacionada ao capital simbólico que possuem.

FIGURA 1

Rede cognitiva da área de ciência da informação, no Brasil

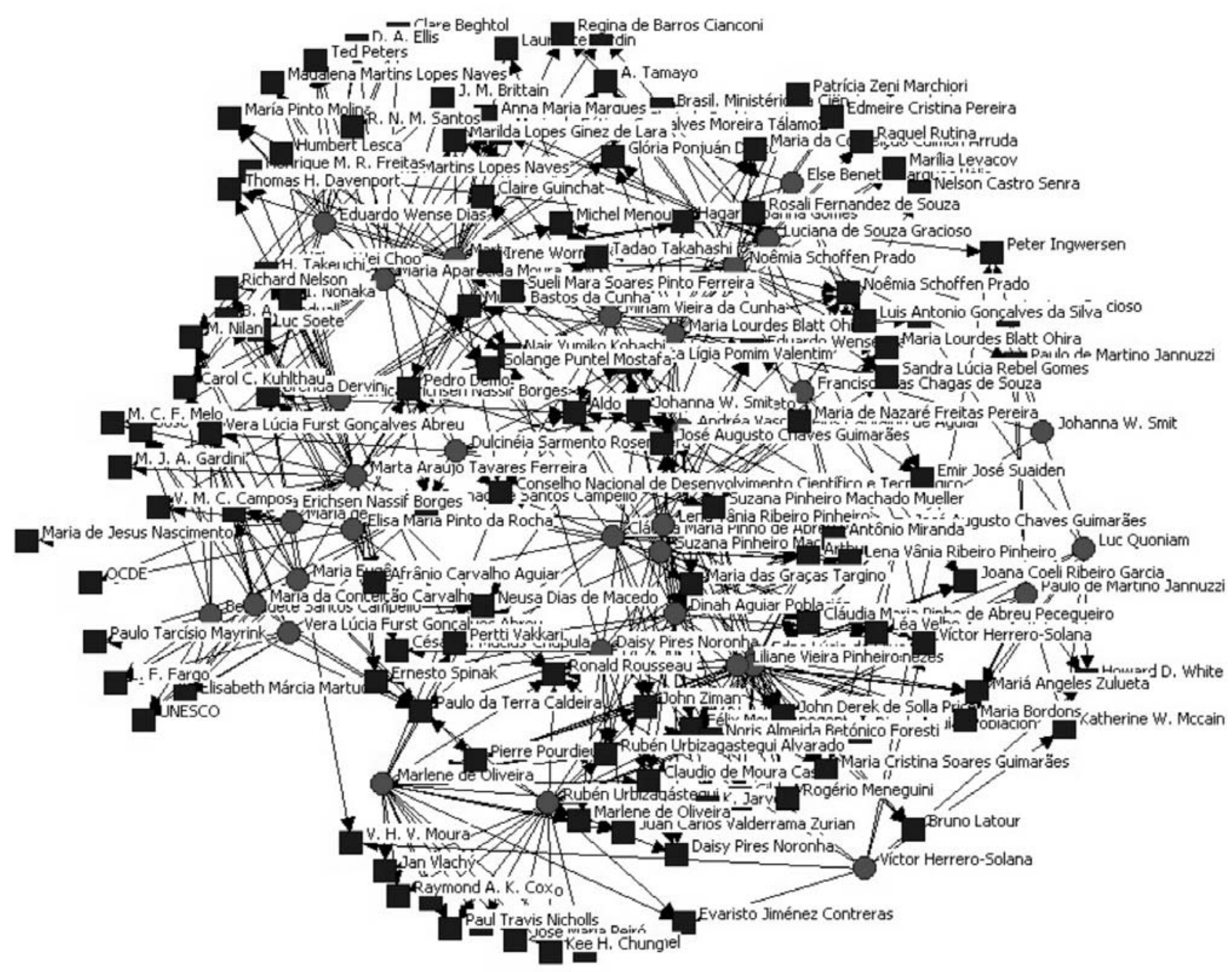

Fonte: dados da pesquisa. 
Ao estudar as redes, Tuire e Erno (2001) concluíram que as relações são mais densas no interior das universidades, onde a passagem de comunicação é maior. Isso demonstra que as relações são estabelecidas em função da proximidade institucional, seja por cursar uma pós-graduação, ou por trabalhar na mesma instituição. Cada pesquisador vai tecendo as suas relações ao longo da carreira acadêmica, com pessoas com quem trabalha diretamente ou com os autores que cita. Elias (1994) destacou que

[...] as relações conferidas a duas pessoas e suas histórias individuais nunca são exatamente idênticas. Cada pessoa parte de uma posição única em sua rede de relações e atravessa uma história até chegar a morte.

\section{As comunidades estabelecidas pelas citações}

Os autores se posicionam na rede de acordo com as relações que estabelecem, e o posicionamento próximo pode ser um indicador da formação de comunidades dentro da rede. Como explica Capra (2002, p. 119), "cada comunidade gera pensamentos e um significado, os quais dão origem a novas comunicações".

Os sistemas são organizados em rede ou comportam redes menores dentro dos seus limites (CAPRA, 2002), assim como ocorre no sistema científico, pois um grupo de agentes forma um sistema científico apenas quando estão estruturados, ou seja, mantêm alguma relação ou influência entre si, compartilham o mesmo espaço, são conduzidos pelas mesmas regras, dependem dos mesmos recursos e/ou são afetados pelo mesmo sistema externo de atuação e planejamento (MALTRÁS BARBA, 2003).

As relações são estabelecidas quando os pesquisadores partilham interesses e aceitam as idéias dos outros pesquisadores, pois, como ressalta Maturana (2001), a relação social está fundada na aceitação mútua. Ao possuírem interesses, valores e crenças comuns, os indivíduos criam uma identidade entre os membros da rede social, baseando-se na sensação de fazer parte de um grupo maior (CAPRA, 2002).

As comunidades existentes em uma área do conhecimento podem ser visualizadas a partir da formação de grupos que desenvolvem estudos com temáticas semelhantes e que recorrem às idéias dos mesmos autores e trabalhos. Na pesquisa realizada, as comunidades visualizadas a partir da rede de autores da área de ciência da informação, no Brasil, foram evidenciadas a partir das relações mais eminentes estabelecidas. Entretanto, vale ressaltar que essas comunidades não formam grupos isolados dentro da rede, pois alguns autores podem estar inseridos em mais de uma comunidade e são, dessa forma, os elos que ligam as comunidades entre si.

As comunidades foram identificadas a partir da análise de co-citação de autores que citaram uma mesma parelha ou grupo de autores. Acredita-se que, nesse caso, exista um compartilhamento de idéias ou o desenvolvimento de pesquisas com temáticas semelhantes, compondo assim uma comunidade que, em primeiro momento, não estaria visível.

Para fins desta pesquisa, verificou-se a formação de comunidades entre os autores focais da rede, ou seja, os mais produtivos e que demonstram mais relações. Vale ressaltar que a ordem de demonstração das comunidades não é um indicador da relevância dessa comunidade na rede.

- Comunidade A: essa comunidade é formada por Daisy Pires Noronha (USP), Dinah Aguiar Población (USP), Edna Lúcia da Silva (UFSC), Estera Muszkat Menezes (UFSC), Liliane Vieira Pinheiro (UFSC), Cláudia Maria Pinho de Abreu Pecegueiro (UFMA), Rubén Urbizagástegui Alvarado (University of Califórnia), José Augusto Chaves Guimarães (Unesp), Lena Vânia Ribeiro Pinheiro (Ibict), Luc Quonian (USP) Suzana Pinheiro Machado Mueller (UnB) e Marlene de Oliveira (UFMG) (figura 2, a seguir).

Verifica-se que os autores desta comunidade desenvolvem pesquisas em linhas sobre comunicação científica, canais de comunicação, produção científica e/ou bibliometria. Entretanto, alguns autores atuam em linhas que aparentemente não têm relação com o tema geral da comunidade, como organização da informação e teoria, epistemologia e interdisciplinaridade da ciência da informação.

São ainda fatores de proximidade dos autores a co-autoria em trabalhos e a integração dos grupos de pesquisa. As autoras Daisy Pires Noronha e Dinah Aguiar Población são co-autoras, juntamente com Marlene de Oliveira, são integrantes do Núcleo de Produção Científica (USP). Edna Lúcia da Silva, Estera Muszkat Menezes e Liliane Vieira Pinheiro também são co-autoras e participam do Núcleo de Estudos em Informação e Mediações Comunicacionais Contemporâneas (UFSC). Observase assim que os pesquisadores que publicam trabalhos juntos são das mesmas instituições, USP e UFSC, o que denota a proximidade institucional entre eles e, conseqüentemente, a troca de informação direta. 
FIGURA 2

Comunidades formadas por pesquisadores mais produtivos da área de ciência da informação, no Brasil
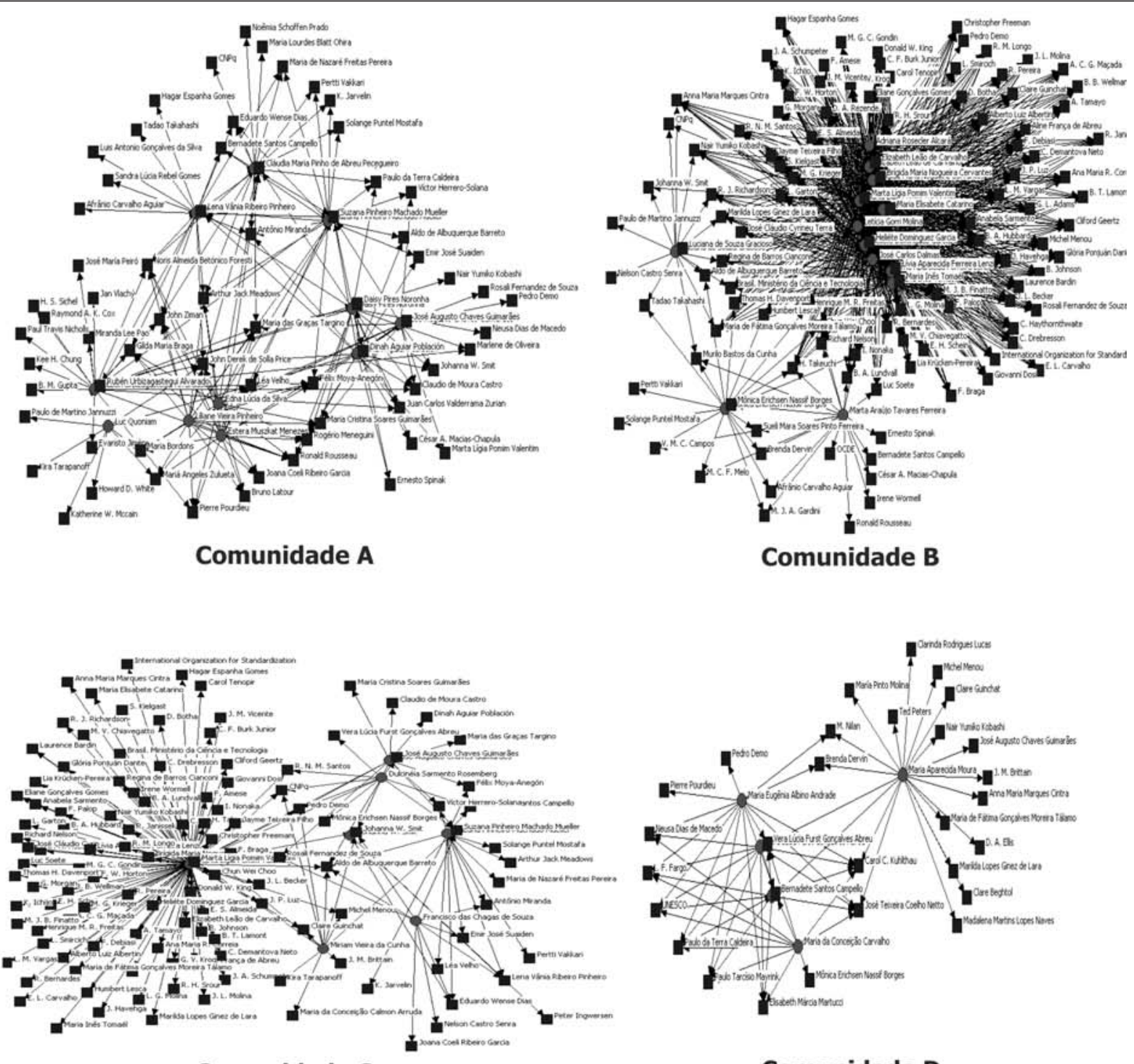

Comunidade C

\section{Comunidade D}

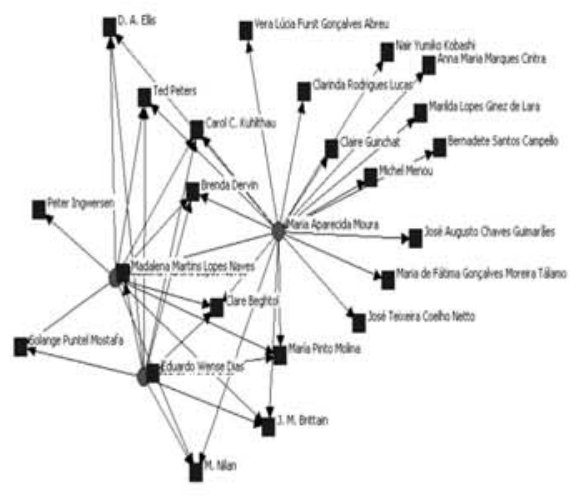

Comunidade E 
Alguns pesquisadores participam de outros grupos além dos mencionados aqui, o que denota a sua atuação em outras linhas de pesquisa e também a possibilidade de formarem outras comunidades, como ocorre com José Augusto Chaves Guimarães e Suzana Pinheiro Machado Mueller. Isso se deve às linhas de pesquisa desenvolvidas por esses pesquisadores.

- Comunidade B: composta por Marta Lígia Pomim Valentim (Unesp), Letícia Gorri Molina (UEL), Adriana Rosecler Alcará (UEL), Brígida Maria Nogueira Cervantes (UEL), Elizabeth Leão de Carvalho (UEL), Lívia Aparecida Ferreira Lenzi (UEL), Maria Elisabete Catarino (UEL), Maria Inês Tomaél (UEL), Heliéte Dominguez Garcia (UEL), José Carlos Dalmas (UEL), Marta Araújo Tavares Ferreira (Centro Universitário UMA), Mônica Erichsen Nassif Borges (UFMG), Luciana de Souza Gracioso (UFSCar) e Elisa Maria Pinto da Rocha (Fundação João Pinheiro) (figura 2).

Nessa comunidade, há um grupo altamente denso, composto por autores que compartilham a autoria em dois artigos científicos e que, na época de publicação do artigo, mantinham vínculos com a mesma instituição, a Universidade Estadual de Londrina (UEL), e eram integrantes do grupo de pesquisa Informação e Inteligência Organizacional, que, na época, era vinculado à mesma instituição, e que atualmente está vinculado a Unesp.

Além da co-autoria, o interesse em temas de pesquisa semelhantes contribui para a sua formação. Adriana Rosecler Alcará, Brígida Maria Nogueira Cervantes, Maria Elisabete Catarino e Maria Inez Tomaél são integrantes do grupo Redes de Conhecimento e Informação (UEL). Adriana Rosecler Alcará e Maria Inez Tomaél atuam nas linhas Redes Sociais: espaços da informação e Informação para Inovação, enquanto que Brígida Maria Nogueira Cervantes e Maria Elisabete Catarino atuam na linha Uso de Ontologias para a Representação do Conhecimento.

Marta Lígia Valentim Pomim e Letícia Gorri Molina atuam na linha de pesquisa Informação, Conhecimento e Tecnologia. A autora Mônica Erichsen Nassif Borges desenvolve pesquisas na linha Inteligência Organizacional e Competitiva, enquanto que Marta Araújo Tavares Ferreira estuda o Planejamento e Gestão em Turismo.

É interessante notar que o surgimento de focos temáticos como a gestão do conhecimento e inteligência social e organizacional, que intensificam a relação entre informação e conhecimento, esquematizam nova assimetria da pesquisa em ciência da informação, no Brasil, pois promovem a migração de tecnologias e estratégias de tratamento e recuperação para novos cenários organizacionais, assim como reativam a relação entre a informação e o texto, explorando as novas mídias e as formas de interação (sincrônicas e assincrônicas) no trabalho intelectual cooperativo (GONZÁLEZ DE GÓMEZ, 2000).

- Comunidade C: Dulcinéia Sarmento Rosemberg (UFES), Johanna Wilhelmina Smit (USP), José Augusto Chaves Guimarães (Unesp), Miriam Vieira da Cunha (UFSC), Marta Lígia Pomim Valentim (Unesp), Francisco das Chagas de Souza (UFSC) e Suzana Pinheiro Machado Mueller (UnB) compõem essa comunidade, que está relacionada ao estudo dos profissionais da informação (figura 2).

Os autores Marta Lígia Pomim Valentim, José Augusto Chaves Guimarães, Johanna Wilhelmina Smit e Miriam Vieira da Cunha integram, entre outros, o grupo Formação e atuação profissional na área de informação e atuam na linha de pesquisa Formação de Profissionais da Informação. A autora Suzana Pinheiro Machado Mueller desenvolve pesquisas na linha Mercado de Trabalho e Formação do Profissional da Informação, que está em consonância com a linha pesquisada pelos demais autores, sendo que a autora Miriam Vieira da Cunha também atua na linha Mercado de Trabalho dos Profissionais da Informação.

O autor Francisco das Chagas de Souza participa da linha Informação, Comunicação, Educação e Sociedade. Apesar de não estar associado, no Diretório de Grupos de Pesquisa, a alguma linha que enfoque diretamente os profissionais da informação, esse autor tem trabalhos publicados com tal temática. Vale também destacar que ele, assim como Miriam Vieira da Cunha, são vinculados à linha de pesquisa Profissional da Informação do Programa de Pós-Graduação em Ciência da Informação da UFSC.

Observa-se que os pesquisadores compartilham as citações aos mesmos autores, por atuarem em linhas de pesquisa que têm como enfoque o profissional da informação.

- Comunidade D: formada por Bernadete Santos Campello (UFMG), Maria da Conceição Carvalho (UFMG), Maria Eugênia Albino Andrade (UFMG), Vera Lúcia Furst Gonçalves Abreu (UFMG) e Maria Aparecida Moura (UFMG) (figura 2). Os autores dessa 
comunidade estão ligados à Universidade Federal de Minas Gerais e são co-autores em trabalhos que abordam o tema Biblioteca Escolar, com exceção de Maria Aparecida Moura. Esta, por sua vez, também está ligada a outra comunidade.

Observa-se que Maria Aparecida Moura participa dessa comunidade por atuar nas mesmas linhas de pesquisa que Maria Eugênia Albino Andrade, a saber, Informação, Cultura e Sociedade, Informação, Espaço e Práticas Sociais e Informação, Estado e Sociedade Civil.

Bernadete Santos Campello e Vera Lúcia Furst Gonçalves Abreu atuam na linha de pesquisa Informação Social. Constata-se que o enfoque da atuação das autoras voltase para a informação e a sociedade; pelo interesse comum acabam estabelecendo relações e compondo essa comunidade. Outro fator que contribui para a formação dessa comunidade é a proximidade institucional que as autoras mantêm.

- Comunidade E: Eduardo Wense Dias (UFMG), Maria Aparecida Moura (UFMG) e Madalena Martins Lopes Naves (UFMG) formam essa comunidade (figura 2). Os autores têm vínculos com a mesma instituição, são integrantes do grupo de pesquisa Tratamento da Informação e desenvolvem pesquisas na linha Análise de Assunto.

As autoras Maria Aparecida Moura e Madalena Martins Lopes também atuam na linha de pesquisa Organização e Uso da Informação, ligada ao grupo Organização da Informação em Contextos Digitais (UFMG), do qual são integrantes. Constata-se que o principal fator de formação dessa comunidade é a proximidade que os autores têm, por atuarem na mesma instituição e grupos de pesquisa.

Analisando as comunidades pelas redes egocêntricas dos autores mais produtivos, verifica-se que alguns desses autores não compartilham o mesmo grupo de citações, de modo que integrem ou participem das comunidades mencionadas anteriormente.

Observou-se que o principal fator para a constituição das comunidades identificadas nesta pesquisa foi a atuação em linhas de pesquisa semelhantes, o que demonstra afinidades nos interesses temáticos. Outros fatores também presentes são o vínculo institucional e a publicação de trabalhos em co-autoria, que demonstram a proximidade institucional dos autores. Esse ponto de vista corrobora o pensamento de Tuire e Erno (2001), quando afirmam que os cientistas desenvolvem mais relações dentro das suas disciplinas e, ainda, com pessoas da mesma especialidade ou que usem a mesma teoria ou lidem com problemas similares. Esses autores afirmam que a passagem da comunicação é maior no interior das universidades.

As comunidades identificadas nesta pesquisa foram formadas, principalmente, com base nas citações feitas aos mesmos autores. Para Vanz (2004), a relação que um pesquisador ou um grupo de pesquisadores mantém com determinados autores é denominada "proximidade paradigmática”. A proximidade paradigmática pode ser vista, na presente pesquisa, na formação das comunidades, pois alguns autores, embora atuem em instituições distintas, trazem influências teóricas da instituição em que cursaram a pós-graduação e, principalmente, dos orientadores. Essa influência se reflete nas citações que os pesquisadores fazem aos mesmos autores, trabalhos e teorias.

A proximidade paradigmática está vinculada ao cenário da universidade - o principal local de produção do conhecimento científico da área de ciência da informação, no Brasil. Na universidade moderna, o conhecimento é paradigmático, ou seja, está vinculado a diferentes paradigmas disciplinares (TIFFIN; RAJASINGHAM, 2007).

As redes remetem ao trabalho intelectual coletivizado, que se inicia com a interação e trabalho em grupo de pesquisadores e estudantes, o que Meadows (1999) denomina "trabalho coletivo orientado". A própria estrutura dos programas de incentivo à pesquisa, na graduação, e dos cursos de pós-graduação, na universidade, exige o acompanhamento da atividade de pesquisa por um orientador, em geral um pesquisador experiente. Essa estrutura contribui para que os estudantes também estabeleçam uma relação de proximidade paradigmática, que, para Vanz (2004), pode ser vista através de sua produção intelectual e das citações feitas aos mesmos autores.

Observa-se, ainda, que as relações entre alguns integrantes das comunidades estão explicitadas na sua participação em grupos de pesquisa. A formação dos grupos de pesquisa prevê a interação de pesquisadores e estudantes. A participação em grupos de pesquisa ou a atuação na mesma instituição indicam que há proximidade institucional entre os autores que compõem as comunidades.

Bourdieu (1996, p. 50) argumenta que "um grupo social tem mais oportunidades de existir e subsistir de maneira 
durável quanto mais os agentes que se agrupam para constituí-lo já estejam mais próximos no espaço social" e que "um grupo mobilizado para e pela defesa de seus interesses não pode existir senão ao preço e ao termo de um trabalho coletivo de construção inseparavelmente teórico e prático.”

Com base no exposto, pode-se afirmar que os grupos demonstram as relações formais entre os pesquisadores e que a formação das comunidades, visualizadas neste trabalho, demonstra que pesquisadores que aparentemente não estão ligados compartilham idéias e influências teóricas, estando, assim, relacionados.

Além disso, mesmo os pesquisadores que não estão relacionados diretamente e aparecem em comunidades distintas estão trabalhando para o desenvolvimento e consolidação do campo científico da ciência da informação. Bourdieu (1996, p. 141) afirma que

entre pessoas que ocupam posições opostas em um campo e que parecem radicalmente opostas em tudo, observa-se que há um acordo oculto e tácito a respeito do fato de que vale a pena lutar a respeito das coisas que estão em jogo do campo.

As redes e comunidades estabelecidas não são estanques, pois a rede é mergulhada em fluxos, o movimento nela é contínuo, tudo se encontra em uma situação de passagem, transição e movimento. Capra (2002) afirma que a rede se reconfigura, quando pessoas novas chegam, e muda novamente, ou até deixa de existir, quando as pessoas saem. Assim, as redes cognitivas e as comunidades formadas na ciência da informação configuram-se em um dado momento, de uma determinada forma, com elementos de interação, nós e elos, que, apesar de agora identificados, estão em constante movimento, pois os artigos produzidos serão os nós e os elos que darão origens a novas produções científicas, na área.

\section{CONCLUSÃO}

A produção do conhecimento é um processo coletivo, neste os pesquisadores interagem e se organizam na forma de rede e, na rede, todos os indivíduos estão relacionados. As relações tecidas na produção do conhecimento podem ser observadas a partir das interações entre os pesquisadores, explicitadas na literatura científica pela co-autoria nos trabalhos publicados e pelas citações feitas a outros trabalhos e autores. Nessa rede, os pesquisadores são os nós e as relações os elos da rede.
Entretanto, observa-se que, em uma rede, alguns elementos estão mais próximos, e a proximidade é um indicador de tais pesquisadores formam uma comunidade, pois partilham interesses, citações e opiniões. Essas comunidades são vistas como redes menores, dentro dos limites da rede.

Dessa maneira, constatou-se que as redes cognitivas mais significativas na construção do conhecimento científico da ciência da informação, no Brasil, foram constituídas pelos autores mais produtivos e pelos autores por eles mais citados. Há um grupo mais produtivo - pesquisadores mais engajados nas atividades de pesquisa da área - composto por $16,95 \%$ dos autores que publicaram, no período analisado. Desses autores mais produtivos, 86\% são docentes das instituições de ensino, no Brasil, e atuam nas áreas de biblioteconomia e ciência da informação, o que demonstra que o conhecimento produzido na área está atrelado às instituições de ensino.

Tais autores se relacionam em torno dos autores que citam e constituem comunidades a partir das relações estabelecidas pelas citações. Essas comunidades são recortes da rede e podem ser entendidas como as principais redes cognitivas da área. Foram identificadas, com base no enfoque das redes egocêntricas, que possibilita escolher os nós focais da rede e suas conexões, cinco comunidades.

As comunidades foram compostas pelo compartilhamento de citações aos mesmos autores. Assim, constatouse que os principais fatores intervenientes na sua formação é a proximidade paradigmática, entendida como a influência que os pesquisadores recebem, ao longo de sua formação acadêmica, e que os leva a incorporar teorias, paradigmas e tendências de pesquisa, ocasionando no uso da mesma base teórica e dos trabalhos dos mesmos autores. Outro fator interveniente na constituição dessas comunidades é a proximidade institucional, visto que os pesquisadores trabalham juntos, desenvolvem interesses comuns e atuam em colaboração.

$\mathrm{Na}$ rede tecida, alguns autores se destacam pelo número de citações recebidas. Acredita-se que o fato de serem mais citados demonstra autoridade na área e que as suas idéias tendem a ser mais aceitas e utilizadas, influenciando a produção do conhecimento científico da ciência da informação brasileira.

Com base nos resultados obtidos, conclui-se que a ciência da informação brasileira se desenvolve ligada a um grupo 
As redes cognitivas na ciência da informação brasileira: um estudo nos artigos científicos publicados nos periódicos da área

influente de pesquisadores - principais autores dos artigos científicos publicados - que atua em universidades e determina os temas de pesquisa a área. Portanto, esse grupo acaba dominando as relações que são estabelecidas para embasar o desenvolvimento dos estudos e pesquisas e que, conseqüentemente, é importante para tecer a interdisciplinaridade e os interesses da área no país.

Vale destacar que a pesquisa que origina este artigo mostra apenas algumas facetas da produção do conhecimento e das relações estabelecidas nesse processo, na área de ciência da informação, no Brasil, a partir de um recorte nos artigos científicos e autores mais produtivos e mais citados. Por isso, tornam-se necessários outros estudos para que se possa ter um panorama interdisciplinar mais aprofundado da área e também detectar outros fatores intervenientes no estabelecimento das relações.

A pesquisa desenvolvida comprovou que o mapeamento de redes cognitivas, usando como instrumento as técnicas bibliométricas, especificamente a análise de citação e de co-citação, foi útil como uma possibilidade para revelar os padrões e os elementos-chave na produção científica no campo de conhecimento em ciência da informação do Brasil. Por meio dos nós e das conexões estabelecidas o conhecimento científico foi representado, mostrando os seus elementos, os seus atributos, as suas instâncias e as suas características mais marcantes. Mostrou igualmente que a natureza e a extensão dos resultados estarão condicionadas às informações obtidas a partir do recorte escolhido e da pertinência de tais informações para os objetivos traçados na pesquisa.

Artigo submetido em 07/10/2008 e aceito em 08/12/2008.

\section{REFERENNCIAS}

BARReto, A. A. de. A condição da informação. São Paulo em Perspectiva, São Paulo, v. 16, n. 3, p. 67-74, 2002

BORGATTI, S. P.; EVERETT, M. G.; FREEMAN, L. C. Ucinet for windows: software for social network analysis. Harvard: Analytic Technologies, 2002

BOURDIEU, P. As razões práticas: sobre a teoria da ação. Campinas: Papirus, 1996

Homo academicus. Paris: Lês Éditions de Minut, 1984.

BRAGA, G. M. Informação, ciência da informação: breves reflexões em três tempos. Ciência da Informação, Brasília, v. 24, n. 1, p. 84-88, jan./abr. 1995.

Relações bibliométricas entre a frente de pesquisa (Research Front) e revisões da literatura: estudo aplicado à ciência da informacão. 1972. Dissertação (Mestrado em Ciência da Informação)- IBICT/ Universidade Federal do Rio de Janeiro, Rio de Janeiro, 1972.

; OBERHOFER, C. A. Diretrizes para a avaliação de periódicos científicos e técnicos brasileiros. Revista Latino-Americana de Documentação, Rio de Janeiro, v. 2, n. 1, p. 27-31, jun. 1982.

CAPRA, F. A teia da vida: uma nova compreensão dos sistemas vivos. 9. ed. São Paulo: Cultrix, 2000.

As conexões ocultas: ciência para uma vida sustentável. 2. ed. São Paulo: Cultrix, 2002

COORDENACÃO DE APERFEIÇOAMENTO DE PESSOAL DE ENSINO SUPERIOR - CAPES. Qualis. Disponível em: <http:// qualis.capes.gov.br/>. Acesso em: 21 jun. 2006.

DELEUZE, G.; GUATTARI, F. Mil platôs: capitalismo e esquizofrenia. Rio de Janeiro: Ed. 34, 1995.

DRESDEN, A. A report on the scientific work of the Chicago section, 1897-1922. Bulletin of the American Mathematical Society, Lancaster, n. 28, p. 303-307, July 1922.

ELIAS, N. A sociedade dos indivíduos. In: A sociedade dos indivíduos. Rio de Janeiro: Jorge Zahar, 1994. Parte I.

FOULCAUlT. M. A arqueologia do saber. 4. ed. Rio de Janeiro: Forense Universitária, 1995

GONZÁLEZ DE GÓMEZ, M. N. Metodología de pesquisa no campo da ciência da informação. DataGramaZero - Revista de Ciência da Informação, Rio de Janeiro, v. 1, n. 6, dez. 2000.

Novos cenários políticos para a informação. Ciência da Informação, Brasília, v. 31, n. 1, p. 27-40, jan./abr. 2002.

HANNEMAN, R. A. Introducción a los métodos del análisis de redes sociales. Riverside: Universidade de California, 2001. Disponível em: <http:/ /revista-redes.redires.es/webredes/textos/introduc. pdf $>$. Acesso em: 03 jan. 2007.

LATOUR, B. Jamais fomos modernos: ensaio de antropologia simétrica. Rio de Janeiro: Ed. 34, 1994.

LE COADIC, Y. F. A ciência da informação. 2. ed. Brasília: Briquet de Lemos, 2004.

LOTKA, A. J. The frequency distribution of scientific productivity. Journal of the Washington Academy of Sciences, Washington, v. 16, n. 12, p. 317-323, jun. 1926. 
MALTRÁS BARBA, B. Los indicadores bibliométricos: fundamentos y aplicación al análisis de la ciencia. Gijón: Trea, 2003.

MATURANA, H. Cognição, ciência e vida cotidiana. Belo Horizonte: UFMG, 2001.

; VARELA, F. A árvore do conhecimento: as bases biológicas do entendimento humano. Campinas: Editorial Psy II, 1995.

MEADOWS, J. A. A comunicação científica. Brasília: Briquet de Lemos, 1999.

MORIN, E. Introdução ao pensamento complexo. Lisboa: Instituto Piaget, 1991.

OLIVEIRA, M.; MOTA, F. R. L.; URBIZAGÁTESGUI ALVARADO, R. Comunidade científica e cientificidade em Ciência da Informação. In: CONGRESSO NACIONAL DE BIBLIOTECÁRIOS, ARQUIVISTAS E DOCUMENTALISTAS, 8., 2004, Estoril. Anais... Lisboa: ABAD, 2004. p. 1-12.

PINHEIRO, L. V. R. Campo interdisciplinar da ciência da informação: fronteiras remotas e recentes. In: (Org.). Ciência da informação, ciências sociais e interdisciplinaridade. Brasília: IBICT, 1999.

PINHEIRO, L. V. R.; LOUREIRO, J. M. M. Traçados e limites da ciência da informação. Ciência da Informação, Brasília, v. 24, n. 1, p. 42-53, jan./abr. 1995 .

SANTOS, N. B. dos. A informação e o paradigma holográfico: a utopia de Vannevar Bush. DataGramaZero - Revista de Ciência da Informação, Rio de Janeiro, v. 3, n. 6, dez. 2002.

SARACEVIC, T. Ciência da informação: origem, evolução e relações. Perspectivas em Ciência da Informação, Belo Horizonte, v. 1, n. 1, p. 41 62, jan./jun. 1996.
SERRES, M. A comunicação. Portugal: Rés Editora, 1967.

SILVA, A. M.; RIBEIRO, F. Das 'ciências' documentais à ciência da informação: ensaio epistemológico para um novo modelo curricular. Porto: Edições Afrontamento, 2002.

SOLLA PRICE, D. J. de. Networks of scientific papers. Science, v. 149, p. 510-515, July 1965.

TAKAHASHI, T. Sociedade da informação no Brasil: livro verde. Brasília: Ministério de Ciência e Tecnologia, 2000.

TIFFIN, J.; RAJASINGHAM, L. Jogar o jogo: o conhecimento nas universidades. In: Artmed, 2007. Cap. 6. A universidade virtual e global. Porto Alegre:

TUIRE, P.; ERNO, L. Exploring invisible scientific communities: studying networking relations within na educational research community, a finish case. Higher Education, Dordrecht, v. 42, p. 493 513, 2001.

URBIZAGÁSTEGUI ALVARADO, R. A lei de Lotka na bibliometria brasileira. Ciência da Informação, Brasília, v. 31, n. 2, p. 14-20, maio/ ago. 2002 .

VANZ, S. A. de S. A produção discente em comunicação: análise das citações das dissertações defendidas nos programas de pós-graduação do Rio Grande do Sul. 2004. 144 f. Dissertação (Mestrado)- Programa de Pós-Graduação em Comunicação e Informação, Universidade Federal do Rio Grande do Sul, Porto Alegre, 2004.

; CAREGNATO, S. E. Estudos de citação: uma ferramenta para entender a comunicação científica. Em Questão, Porto Alegre, v. 9, n. 2, p. 295-307, jul./dez. 2003. 